\title{
Can self-reported cognitive difficulties predict postoperative delirium?
}

\author{
Renée El-Gabalawy (1) - Jordana L. Sommer - W. Alan C. Mutch • \\ Eric Jacobsohn
}

Received: 25 August 2020/Revised: 16 December 2020/Accepted: 16 December 2020/Published online: 28 January 2021

(C) Canadian Anesthesiologists' Society 2021

To the Editor,

Postoperative delirium (POD) is a common and detrimental clinical outcome and preoperative cognitive impairment is a well-established predictor. Though not routinely clinically assessed, national associations (e.g., American College of Surgeons) recommend employing preoperative cognitive assessment. Research supports the use of risk assessment and reduction strategies to mitigate and manage POD. ${ }^{1}$

In research contexts, cognitive assessment measures are administered by trained professionals, display limited variance, identify only severe cognitive deficits, and have poor levels of sensitivity and specificity. ${ }^{2}$ The Nomenclature Consensus Working Group recommends preoperative assessment of patient-reported cognitive concerns, which may more effectively identify subtle and

Eric Jacobsohn-On behalf of the ENGAGES-Canada Winnipeg Researchers.

R. El-Gabalawy ( $₫)$

Department of Anesthesiology, Perioperative and Pain Medicine, University of Manitoba, Winnipeg, MB, Canada

e-mail: renee.el-gabalawy@umanitoba.ca

Department of Clinical Health Psychology, University of Manitoba, Winnipeg, MB, Canada

Department of Psychology, University of Manitoba, Winnipeg, MB, Canada

Department of Psychiatry, University of Manitoba, Winnipeg, MB, Canada

J. L. Sommer

Department of Anesthesiology, Perioperative and Pain Medicine, University of Manitoba, Winnipeg, MB, Canada mild cognitive deficits; however, existing measures do not effectively capture the spectrum of cognitive difficulties.

Two distinct newer measures of cognitive functioning are the National Institutes of Health's Patient-Reported Outcome Measurement Information System (PROMIS) Applied Cognition General Concerns and Abilities Short Forms (access full measures at healthmeasures.net), which are validated self-report measures. ${ }^{3,4}$ Scores can be compared with general population norms. The utility of these scales in the perioperative literature is unclear. This analysis examined the association between these scales preoperatively and POD symptom severity.

We analyzed discontinued non-cardiac data collected from the Electroencephalography Guidance of Anesthesia to Alleviate Geriatric Syndromes (ENGAGES-CANADA; NCT02692300) study. ${ }^{4}$ The University of Manitoba Research Ethics Board provided ethical approval (09-032015). The sample consisted of older adults $\geq 60 \mathrm{yr}(n=$

Department of Psychology, University of Manitoba, Winnipeg, MB, Canada

W. A. C. Mutch

Department of Anesthesiology, Perioperative and Pain Medicine, University of Manitoba, Winnipeg, MB, Canada

Canada North Concussion Network (www.CNCN.ca), Winnipeg, MB, Canada

E. Jacobsohn

Department of Anesthesiology, Perioperative and Pain Medicine, University of Manitoba, Winnipeg, MB, Canada 
Table 1 Preoperative cognitive measure predictors of postoperative delirium symptom severity

\begin{tabular}{|c|c|c|c|c|c|c|}
\hline \multirow[b]{3}{*}{ Model 1} & \multicolumn{6}{|l|}{ POD peak score } \\
\hline & \multicolumn{2}{|l|}{ Step 1} & \multicolumn{2}{|l|}{ Step 2} & \multicolumn{2}{|l|}{ Step 3} \\
\hline & $\begin{array}{l}R^{2}=0.02 \\
b(95 \% \mathrm{CI})\end{array}$ & $\begin{array}{l}R^{2} \Delta=0.0 \\
P \text { value }\end{array}$ & $\begin{array}{l}R^{2}=0.14 \\
b(95 \% \mathrm{CI})\end{array}$ & $\begin{array}{l}R^{2} \Delta=0.12 \\
P \text { value }\end{array}$ & $\begin{array}{l}R^{2}=0.20 \\
b(95 \% \mathrm{CI})\end{array}$ & $\begin{array}{l}R^{2} \Delta=0.05 \\
P \text { value }\end{array}$ \\
\hline Age & $0.03(-0.06$ to 0.12$)$ & 0.54 & $0.02(-0.07$ to 0.10$)$ & 0.72 & $0.04(-0.05$ to 0.12$)$ & 0.38 \\
\hline Sex & $-0.03(-0.09$ to 0.02$)$ & 0.24 & $-0.03(-0.08$ to 0.03$)$ & 0.36 & $-0.02(-0.07$ to 0.03$)$ & 0.43 \\
\hline $\begin{array}{r}\text { History of } \\
\text { delirium }\end{array}$ & $-0.16(-1.82$ to 1.50$)$ & 0.85 & $-0.27(-1.84$ to 1.29$)$ & 0.73 & $-0.46(-1.99$ to 1.07$)$ & 0.55 \\
\hline $\begin{array}{l}\text { PROMIS } \\
\text { Cognitive } \\
\text { Concerns }\end{array}$ & - & - & $0.29(0.12$ to 0.45$)$ & 0.001 & $0.23(0.06$ to 0.40$)$ & 0.008 \\
\hline \multirow[t]{3}{*}{ Short Blessed Test } & - & - & - & - & $0.23(0.03$ to 0.43$)$ & 0.02 \\
\hline & \multicolumn{6}{|l|}{ POD peak score } \\
\hline & \multicolumn{2}{|l|}{ Step 1} & \multicolumn{2}{|l|}{ Step 2} & \multicolumn{2}{|l|}{ Step 3} \\
\hline Model 2 & $\begin{array}{l}R^{2}=0.02 \\
b(95 \% \mathrm{CI})\end{array}$ & $\begin{array}{l}R^{2} \Delta=0.02 \\
P \text { value }\end{array}$ & $\begin{array}{l}R^{2}=0.18 \\
b(95 \% \mathrm{CI})\end{array}$ & $\begin{array}{l}R^{2} \Delta=0.16 \\
P \text { value }\end{array}$ & $\begin{array}{l}R^{2}=0.25 \\
b(95 \% \mathrm{CI})\end{array}$ & $\begin{array}{l}R^{2} \Delta=0.07 \\
P \text { value }\end{array}$ \\
\hline Age & $0.03(-0.06-0.12)$ & 0.53 & $-0.00(-0.09$ to 0.08$)$ & 0.94 & $0.02(-0.06$ to 0.10$)$ & 0.62 \\
\hline Sex & $-0.03(-0.09-0.02)$ & 0.23 & $-0.07(-0.12$ to -0.01$)$ & 0.02 & $-0.06(-0.11$ to -0.01$)$ & 0.03 \\
\hline History of delirium & $-0.16(-1.81-1.49)$ & 0.85 & $0.02(-1.50$ to 1.53$)$ & 0.98 & $-0.24(-1.72$ to 1.24$)$ & 0.75 \\
\hline $\begin{array}{l}\text { PROMIS Cognitive } \\
\text { Abilities }\end{array}$ & - & - & $0.26(0.13$ to 0.39$)$ & $<0.001$ & $0.23(0.11$ to 0.36$)$ & $<0.001$ \\
\hline Short Blessed Test & - & - & - & - & $0.25(0.07$ to 0.43$)$ & 0.009 \\
\hline
\end{tabular}

Dependent variable $=$ POD severity; $b=$ unstandardized regression coefficient; PROMIS = Patient-Reported Outcomes Measurement Information System. We reverse-coded the PROMIS Cognitive Abilities thus higher scores on all cognitive measures indicates poorer cognitive functioning.

$\mathrm{CI}=$ confidence interval POD $=$ postoperative delirium

101) undergoing a major elective non-cardiac surgery at one of two large tertiary hospitals in Manitoba requiring a minimum stay of two days postoperatively. Those who underwent neurosurgical or cerebrovascular procedures, screened positive for delirium preoperatively, had a history of intraoperative awareness, or had a second surgery scheduled within five days of their first surgery were excluded. This initial trial examined whether intraoperative electroencephalographic (EEG) guidance of anesthetic depth during general anesthesia decreased rates of POD. An interim analysis showed no statistically significant difference between the naive and EEG-guided groups and recruitment was discontinued for non-cardiac surgeries. This letter describes a study undertaken to fulfill one of the secondary aims of ENGAGES-CANADA, using the discontinued non-cardiac data.

Cognitive functioning was assessed approximately one week preoperatively using the Short Blessed Test (SBT) and the PROMIS Cognitive Concerns-4A and Abilities-4A measures. ${ }^{2,3}$ Patients completed the PROMIS measures independently and research personnel administered the SBT. Postoperative delirium was assessed daily up to five days postoperatively by trained personnel using the Confusion Assessment Method-Severity measure. ${ }^{5} \mathrm{We}$ examined POD symptom severity using a peak POD long form score (range $0-19$ ) on any postoperative day. ${ }^{5}$

Hierarchical linear regressions assessed the relationships between PROMIS cognitive measures and POD symptom severity, with each PROMIS measure assessed in a separate model. First, we entered established predictors of POD (age, sex, history of delirium). The PROMIS cognitive measures were entered in a second step and an objective measure (SBT) was entered in a third step.

Incident POD occurred in $11.9 \%$ of patients $(n=12)$; the mean (standard deviation [SD]) CAM-S score was 4.2 (2.6). The mean (SD) age of the cohort was 69 (6.4) yr, and $64.4 \%$ were male. No assumptions of linear regression were violated. Both PROMIS scores were associated with POD symptom severity and explained unique variance ( $>15 \%$ for cognitive abilities) in POD symptoms beyond 
the influence of established predictors. Including the SBT also explained unique variance $(5-7 \%$; Table 1$)$.

Results highlight the utility of these brief ( $\sim$ one minute), easy to administer, self- report measures. A combination of objective and patient-reported measures could potentially produce a more comprehensive cognitive assessment preoperatively and taken together may increase our understanding of patient risk for POD. Limitations of this study include use of single daily POD assessments (which may have decreased the detection of delirium) and a small sample size, restricting an examination of incident POD.

These findings may inform future research, and potentially the implementation of preoperative cognitive screening. The four-item self-administered PROMIS Cognitive Abilities scale may be a useful and simple addition to the clinician's armamentarium for prospective identification of patients at risk of POD.

\section{Disclosures None}

Funding information This work was supported by Start-Up Funding and the Department of Anesthesiology, Perioperative and Pain Medicine at the University of Manitoba.

Trial registration NCT02692300; https://clinicaltrials.gov/ct2/ show/NCT02692300.
Editorial responsibility This submission was handled by Dr. Gregory L. Bryson, Former Deputy Editor-in-Chief, Canadian Journal of Anesthesia.

\section{References}

1. Jin Z, Hu J, Ma D. Postoperative delirium: perioperative assessment, risk reduction, and management. Br J Anaesth 2020; 125: $492-504$

2. Barbic D, Kim B, Salehmohamed $Q$, Kemplin $K$, Carpenter $C R$, Barbic SP. Diagnostic accuracy of the Ottawa 3DY and Short Blessed Test to detect cognitive dysfunction in geriatric patients presenting to the emergency department. BMJ Open 2018; . https:// doi.org/10.1136/bmjopen-2017-019652.

3. Howland M, Tatsuoka C, Smyth KA, Sajatovic M. Evaluating PROMIS(®) applied cognition items in a sample of older adults at risk for cognitive decline. Psychiatry Res 2016; 247: 39-42.

4. Deschamps A, Saha T, El-Gabalawy R, et al. Protocol for the electroencephalography guidance of anesthesia to alleviate geriatric syndromes (ENGAGES-Canada) study: a pragmatic, randomized clinical trial. F1000Res 2019; DOI: 10.12688/ f1000research.19213.1.

5. Inouye SK, Kosar CM, Tommet D, et al. The CAM-S: development and validation of a new scoring system for delirium severity in 2 cohorts. Ann Intern Med 2014; 160: 526-33.

Publisher's Note Springer Nature remains neutral with regard to jurisdictional claims in published maps and institutional affiliations. 